\title{
Fenestração apical decorrente de traumatismo dentário em paciente pediátrico: relato de caso
}

Apical fenestration due to dental traumatism in a pediatric patient: case report

Fenestración apical por traumatismo dental en paciente pediátrico: reporte de caso

Danyllo Guimarães Morais BARROS ${ }^{1}$

Diego Filipe Bezerra SILVA ${ }^{2}$

Daliana Queiroga de Castro GOMES ${ }^{3}$

${ }^{1}$ Graduando do curso de Odontologia da Universidade Estadual da Paraíba - UEPB, 58429-600, Campina Grande-PB, Brasil

${ }^{2}$ Mestrando do Programa de Pós-Graduação em Odontologia da Universidade Estadual da Paraíba - UEPB, 58429-600, Campina Grande-PB, Brasil ${ }^{3}$ Professora Doutora do Programa de Pós-Graduação em Odontologia, Universidade Estadual da Paraíba - UEPB, 58429-600 Campina Grande-PB, Brasil

\section{Resumo}

Introdução: A alveólise é uma condição patológica ósseo-gengival de baixa ocorrência, decorrente do deslocamento da raiz do dente decíduo em direção à lâmina óssea alveolar externa, com rompimento do osso e da gengiva ou mucosa alveolar, até se tornar clinicamente visível na cavidade oral. Objetivo: Relatar um caso clínico de alveólise, do tipo fenestração apical (FA), em paciente pediátrico com história de traumatismo dentário na região anterior da maxila. Relato do caso: Paciente do sexo masculino, seis anos de idade, apresentou-se com dente 51 mesializado, extruído, com exposição do ápice da raiz na região vestibular maxilar da cavidade oral, com tecido circundante edemaciado e eritematoso, sem sintomatologia dolorosa. Durante a anamnese, a mãe do paciente relatou que o mesmo sofreu uma queda há aproximadamente quatro anos, com consequente traumatismo dentário na região anterior da maxila, porém não procurou-se atendimento odontológico após o ocorrido. A análise radiográfica confirmou a formação dos dentes permanentes sucessores 11 e 21 . O dente 61 estava em processo de rizólise, enquanto que a raiz do dente 51 encontrava-se sem evidências desse processo fisiológico. O diagnóstico clínico foi de alveólise, do tipo FA, e o tratamento de escolha foi a exodontia do dente 51. Após nove dias do procedimento, o paciente retornou e foi observado que a região onde havia sido realizada a exodontia estava apresentando cicatrização satisfatória. Considerações finais: Conclui-se que a alveólise é uma condição de fácil diagnóstico e o tratamento de escolha é a exodontia do dente envolvido e apresenta bom prognóstico.

Descritores: Traumatismos Dentários; Criança; Dente Decíduo; Perda do Osso Alveolar.

\section{Abstract}

Introduction: Alveolysis is a low occurrence bone-gingival pathological condition, due to the displacement of the root of the deciduous tooth towards the outer alveolar bone, with rupture of the bone and gingiva or alveolar mucosa, until it becomes clinically visible in the oral cavity. Objective: To report a clinical case of alveolysis, of the apical fenestration (AF) type, in a pediatric patient with a history of dental trauma in the anterior maxilla. Case report: An 6-year-old male child presented with tooth \#51 mesialized, extruded, with root apex exposure in the maxillary vestibular region of the oral cavity, with surrounding edema and erythematous tissue, without painful symptomatology. During the anamnesis, the patient's mother reported that he suffered a fall approximately four years ago, with consequent dental trauma in the anterior region of the maxilla, but he was not submitted to dental care after the event. Radiographic analysis confirmed the formation of the successor permanent teeth \#11 and \#21. The tooth \#61 was in the process of rhizolysis, while the root of the tooth \#51 was without evidence of this physiological process. The clinical diagnosis was alveolysis, type AF, and the treatment of choice was tooth extraction \#51. After nine days of the procedure, the patient returned and it was observed that the region where the exodontia had been performed was showing satisfactory healing. Final considerations: It is concluded that alveolysis is a condition of easy diagnosis and the treatment of choice is tooth extraction involved and presents a good prognosis.

Descriptors: Tooth Injuries; Child; Tooth, Deciduous; Alveolar Bone Loss.

\section{Resumen}

Introducción: La alveólisis es una afección patológica ósea-gingival de baja ocurrencia que resulta del desplazamiento de la raíz del diente caducifolio hacia la lámina externa del hueso alveolar, con ruptura del hueso y la encía o la mucosa alveolar, hasta que se vuelve clínicamente visible en la cavidad oral. Objetivo: Informar un caso clínico de alveólisis en un paciente pediátrico con antecedentes de traumatismo dental en el maxilar anterior. Reporte de caso: Un paciente masculino de seis años presentó un diente mesializado extruido con exposición al ápice de la raíz en la región vestibular maxilar de la cavidad oral, con edema y tejido eritematoso circundante, sin síntomas dolorosos. Durante la anamnesis, la madre del paciente informó que el paciente sufrió una caída hace aproximadamente cuatro años, con el consiguiente trauma dental en el maxilar anterior, pero no fue sometido a atención dental después de la ocurrencia. El análisis radiográfico confirmó la formación de los dientes permanentes sucesores 11 y 21 . El diente 61 estaba en proceso de rizolisis, mientras que la raíz del diente 51 no tenía evidencia de este proceso fisiológico. El diagnóstico clínico fue alveólisis, tipo fenestración apical, y el tratamiento de elección fue la extracción del diente 51. Después de nueve días del procedimento se observó que la región donde se realizó la extracción mostraba una curación satisfactoria. Consideraciones finales: Se concluye que la alveólisis es una condición fácil de diagnosticar y el tratamiento de elección es la extracción del diente involucrado y tiene un buen pronóstico.

Descriptores: Traumatismos de los Dientes; Niño; Diente Primario; Pérdida de Hueso Alveolar.

INTRODUÇÃO

A alveólise é caracterizada como uma condição patológica decorrente do deslocamento da raiz do dente decíduo em direção à lâmina óssea alveolar externa, com rompimento do osso e da gengiva ou mucosa alveolar, até se tornar clinicamente visível na cavidade oral $^{1}$. Essa patologia é classificada em deiscência, que pode ser parcial ou total, ou em fenestração apical $(F A)^{1,2}$. Na deiscência parcial ocorre exposição da superfície radicular na porção cervical, que pode evoluir em direção apical, quando é classificada como deiscência total 1 . A FA é caracterizada por uma perfuração do osso alveolar e mucosa próxima ao ápice da raiz de um dente decíduo ${ }^{3,4}$ com consequente exposição da porção apical da raiz dentária na cavidade oral ${ }^{1,3}$.

As lesões cariosas e traumatismos 
dentários são fatores etiológicos que resultam em processos graves de inflamação/ infecção ${ }^{5}$, que podem resultar na FA. A disseminação da infecção pulpar de um dente decíduo para a região perirradicular pode levar à reabsorção patológica da raiz do dente decíduo ou à $\mathrm{FA}^{5}$. $\mathrm{O}$ traumatismo dentário em dente decíduo resulta, na maioria das vezes, em luxação dentária, com deslocamento do dente para a região lingual e o ápice no sentido inverso, com rompimento dos tecidos de sustentação, podendo evoluir para um processo inflamatório crônico, resultando em alveólise do tipo $F A^{1}$.

A FA é uma condição rara ${ }^{4}$, tendo uma prevalência que varia de $7,5 \%$ a $20 \%{ }^{5}$. Essa condição acomete principalmente indivíduos do sexo masculino, numa proporção de $4: 1$, com idade de cinco anos, e frequentemente é assintomática ${ }^{6}$. Além disso, afeta ou ocorre, principalmente nos incisivos superiores ${ }^{4}$. A exposição da raiz torna a mesma suscetível à presença de biofilme e à formação de cálculo ${ }^{5}$, bem como pode promover a formação de úlcera na gengiva na área envolvida e desenvolvimento de tecido reacional hiperplásico associado ${ }^{2}$.

O tratamento de escolha da FA é a exodontia do dente afetado, ${ }^{1,2,4}$. Os cirurgiõesdentistas precisam ficar atentos para evitar danos à fina camada de mucosa que recobre a parte central da raiz ${ }^{4}$. Diante do exposto, o objetivo do presente trabalho é relatar um caso clínico de FA em paciente de seis anos de idade, com história de traumatismo dentário na região anterior da maxila.

CASO CLÍNICO

Paciente sexo masculino, seis anos de idade, apresentou-se com queixa principal de "ajeitar o dente da frente que está para fora". $\mathrm{Na}$ anamnese, a mãe do paciente relatou queda do paciente há aproximadamente quatro anos, com consequente traumatismo dentário na região anterior da maxila, sem procura por atendimento odontológico após o ocorrido. Ao exame físico intraoral foram observadas cáries precoces da infância. Ademais, o dente 51 apresentava-se mesializado, extruído, com exposição do ápice da raiz na região vestibular maxilar da cavidade oral com tecido circundante edemaciado e eritematoso, sem sintomatologia dolorosa (Figura 1). Na análise radiográfica, confirmou-se a formação dos dentes permanentes sucessores 11 e 21 e processo de rizólise do dente 61 , enquanto que a raiz do dente 51 não mostrava evidências desse processo fisiológico (Figura 2). O diagnóstico clínico foi de alveólise, do tipo FA, e o tratamento de escolha exodontia do dente 51 (Figuras 3 e 4). Decorridos nove dias após o tratamento, o paciente retornou e foi observado que a região onde havia sido realizada a exodontia estava apresentando boa cicatrização (Figura 5). O paciente permanece em acompanhamento para realização de procedimentos restauradores.

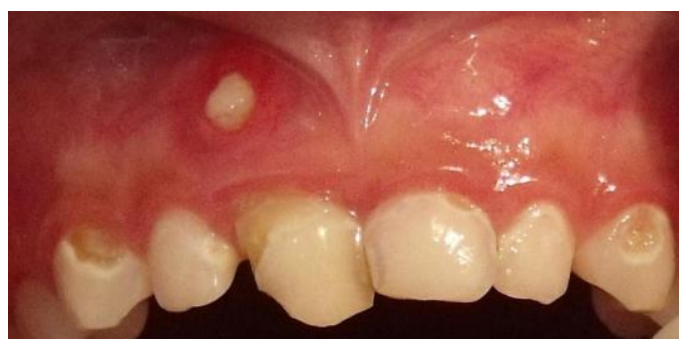

Figura 1: Imagem clínica inicial mostrando exposição vestibular do ápice radicular do dente 51 , com mucosa alveolar circundante eritematosa e levemente edemaciada.

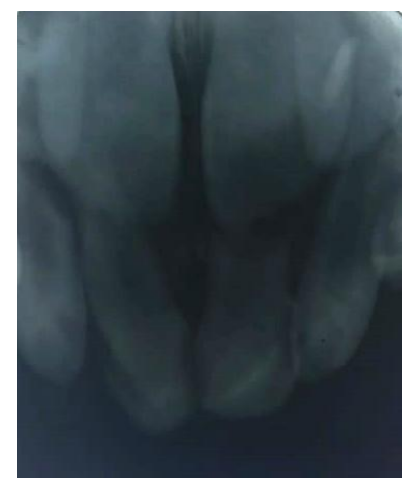

Figura 2: Radiografia periapical da região anterior superior da maxila, revelando a presença dos incisivos permanentes $(11,21)$. Evidenciase, ainda, o dente 61 em processo de rizólise e ausência deste processo no dente 51

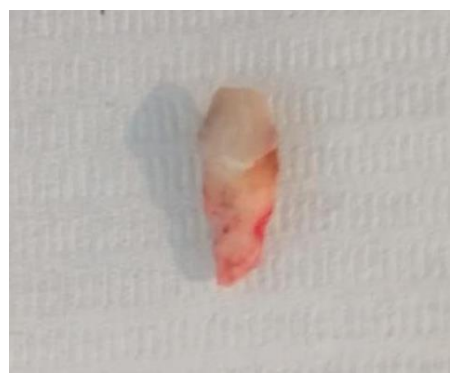

Figura 3: Dente 51 extraído. Nota-se raiz completamente formada, sem sinais de rizólise.

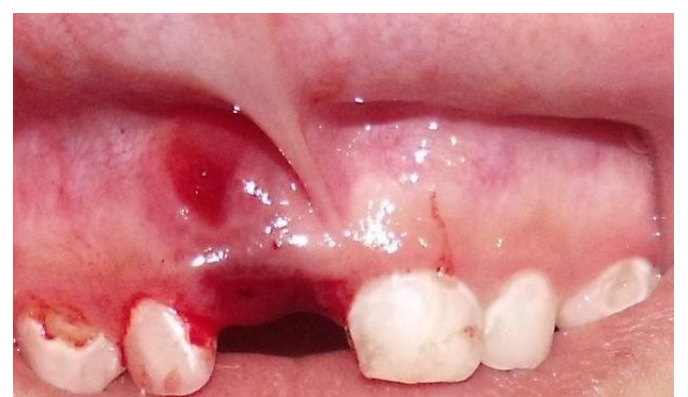

Figura 4: Aspecto clínico imediatamente após exodontia do dente 51.

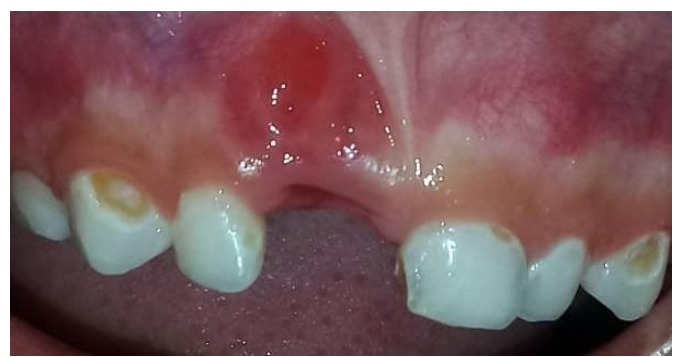

Figura 5. Aspecto clínico nove dias após a exodontia do dente 51. 
DISCUSSÃO

$\mathrm{Na}$ dentição decídua, a incidência de traumas dentários é alta e está relacionada com a idade pré-escolar entre um e três anos, onde as quedas da própria altura é o principal fator etiológico ${ }^{2}$. No presente caso, o paciente compareceu para atendimento com seis anos de idade, porém, segundo relato da responsável, o trauma havia ocorrido quando o paciente tinha aproximadamente dois anos de idade. Este tempo prolongado decorrido entre o traumatismo dentário e o diagnóstico de alveólise, é constatado pelo estudo de Kimura et al. ${ }^{7}$, onde a média de tempo foi de 15 meses. Este tempo de procura por atendimento pode estar relacionado à ausência de sintomatologia dolorosa observada nessa condição.

As características clínicas mais comuns encontradas após as lesões dentárias decorrentes de trauma são subluxação, intrusão e avulsão ${ }^{3}$. Apesar de o traumatismo dentário ser comum em crianças, a ocorrência de alveólise é relativamente baixa ${ }^{1}$. Na série de casos realizada por Kimura et al. ${ }^{7}$, com objetivo de verificar a ocorrência de patologias ósseogengivais decorrentes de trauma em dentes decíduos, foi observado que apenas 9,6\% ( $n=7)$ dos dentes apresentaram FA.

$E m$ relação às sequelas relacionadas à FA em dentes decíduos, existem duas frequentemente relacionadas, a ferida gengival presente na área envolvida e o tecido reacional hiperplásico relacionado à lesão ${ }^{2}$. Este último ocorre quando a irritação do tecido é crônica, o que pode resultar uma lesão hiperplásica ou neoplásica ${ }^{2}$, como fibroma de irritação. No presente caso, foi observado um tecido eritematoso circundando a região de exposição do ápice dentário, com ausência de hiperplasia.

Segundo relatos de casos publicados na literatura, recomenda-se a exodontia do dente envolvido, no caso de alveólise do tipo $\mathrm{FA}^{1,4}$. No estudo de Kimura et al. ${ }^{7}$ foi observado que, em todos os casos de FA, a exodontia do dente envolvido foi o tratamento de escolha. Em consonância com a literatura disponível sobre alveólise, o tratamento de escolha no presente caso também foi a exodontia do dente envolvido. A exposição torna a raiz suscetível à presença de biofilme e à formação de cálculos ${ }^{5}$, o que causa inflamação e pode resultar no desenvolvimento de processos proliferativos não-neoplásicos, como foi observado nos dois casos relatados por Aguiló et al. ${ }^{4}$, onde, após a exodontia dos dentes afetados por alveólise, foi observada a formação de granuloma piogênico. Também podem ocorrer distúrbios na erupção do sucessor permanente em decorrência do dente com FA.

Apesar da alveólise ser considerada uma condição de baixa ocorrência, o profissional deve ter conhecimento dessa condição, bem como realizar o tratamento indicado de forma adequada. Além disso, deve-se realizar um acompanhamento periódico do paciente pelo menos até a erupção do dente sucessor permanente.

CONCLUSÃO

O caso ora relatado constitui um caso característico de alveólise, do tipo FA, em dente decíduo com história de traumatismo dentário prévio. O tratamento de escolha foi a exodontia do dente envolvido, o que foi de acordo com o recomendado pela literatura. Pode-se concluir, também, que a alveólise é uma condição de fácil diagnóstico, o tratamento é simples e de bom prognóstico. Além disso, recomenda-se o acompanhamento periódico do paciente.

\section{REFERÊNCIAS}

1. Sarmento CP, de Almeida CM, dos Santos KSA, Campos FAT; Granville-Garcia AF, Costa EMMB. Alveólise em dente decíduo: relato de caso. J Health Sci. 2017;19(4):228-31.

2. Duarte JA, Lisbôa LMS, Mendes PCA. Alveólise em dente decíduo: relato de caso. Rev Virtual AcBO. 2018;7(3):167-70.

3. Edney MB. Interesting presentation of a retained upper deciduous incisor with apical fenestration. Br Dent J. 2000;188(7):369-70.

4. Aguiló L, Bagán JV. Pyogenic granuloma subsequent to apical fenestration of a primary tooth. J Am Dent Assoc. 2002;133(5):599-602.

5. Triches TC, Paula LK, Filho MX, Bolan M. Apical fenestration and ectopic eruption effects from trauma to primary tooth: a clinical case report. Dent Traumatol. 2011;27(1):74-6.

6. Menéndez OR. Bone fenestration by roots of deciduous teeth. Oral Surg Oral Med Oral Pathol. 1967;24(5):654-8.

7. Kimura JS, Aldrigui JM, de Carvalho $P$, Wanderley MT. Osseo-gingival pathology as sequelae of dental trauma to the primary upper incisor: a case series. Int J Paediatr Dent. 2017;27(2):128-134. 


\section{CONFLITO DE INTERESSES}

Os autores declaram não haver conflitos de interesse

\section{AUTOR PARA CORRESPONDÊNCIA}

\section{Daliana Queiroga de Castro Gomes}

Universidade Estadual da Paraíba - UEPB,

58429-600 Campina Grande-PB, Brasil

e-mail: dqcgomes@hotmail.com 